\title{
Humanitude in the humanization of elderly care: experience reports in a health service
}

\author{
Humanitude na humanização da assistência a idosos: relato de experiência em um serviço de saúde
}

Humanitude en la humanización de la asistencia a ancianos: un relato de experiencia desde un servicio de salud

\section{Rosa Cândida Carvalho Pereira de Melo' ORCID: 0000-0002-0941-407X \\ Paulo Jorge Costa' ORCID: 0000-0003-0761-6548}

Liliana Vanessa Lúcio Henriques' ORCID: 0000-0001-7648-7626

Luiza Hiromi Tanaka" ORCID: 0000-0003-4344-1116

Paulo Joaquim Pina Queirós' ORCID: 0000-0003-1817-612X

João Pärtel Araújo' ORCID: 0000-0003-0037-9383

'Escola Superior de Enfermagem de Coimbra. Coimbra, Portugal.

"Universidade Federal de São Paulo. São Paulo. São Paulo, Brasil.

How to cite this article:

Melo RCCP, Costa PJ, Henriques LVL, Tanaka LH, Queirós PJP, Araújo JP. Humanitude in the humanization of elderly care: experience reports in a health service

Rev Bras Enferm [Internet]. 2019;72(3):825-9. doi: http://dx.doi.org/10.1590/0034-7167-2017-0363

Corresponding Author: Rosa Cândida Carvalho Pereira de Melo E-mail: rosamelo@esenfc.pt

Submission: 06-07-2017 Approval: 01-02-2019

\begin{abstract}
Objective: To describe the experience in the implementation of the Humanitude Care Methodology $(\mathrm{MCH})$ in the humanization of care for the elderly. Methodology: This is an experience report about the implementation of the $\mathrm{MCH}$, in a Health Service in Portugal, with capacity for 30 elderly people, most of them having cognitive alterations. Results: The implementation of the $\mathrm{MCH}$ has shown positive results in the humanization of care for the elderly, namely in the reduction of agitation behaviors and better acceptance of care. There was a change in organizational culture, more focused on the person and on the humanization of care. Conclusion: The results reflect the need to introduce innovative care methodologies in the training of health professionals, with a focus on interaction, for a professionalized relational care that dignifies the person cared for and the care giver.

Descriptors: Humanization of Care; Organizational Innovation; Evidence-Based Nursing; Patient Centered Care; Neurocognitive Disorders; Nurse-Patient Relations.
\end{abstract}

\section{RESUMO}

Objetivo: Relatar a experiência vivida durante a implementação da Metodologia de Cuidado Humanitude na humanização da assistência a idosos. Métodos: Tratase de um relato de experiência sobre a implementação da Metodologia de Cuidado Humanitude em um Serviço de Saúde, em Portugal, com lotação para 30 idosos, tendo a maioria alterações cognitivas. Resultados: A implementação da Metodologia de Cuidado Humanitude demonstrou resultados positivos na humanização da assistência aos idosos, nomeadamente na redução dos comportamentos de agitação e melhor aceitação do cuidado. Verificou-se mudança na cultura organizacional, mais focada na pessoa e na humanização da assistência. Conclusão: Os resultados refletem a necessidade de introduzir metodologias de cuidado inovadoras na formação dos profissionais de saúde, com foco na interação, para um cuidado relacional profissionalizado que dignifique a pessoa cuidada e quem cuida.

Descritores: Humanização da Assistência; Serviço de Saúde; Enfermagem Baseada em Evidências; Assistência Centrada no Paciente; Assistência a Idosos.

\section{RESUMEN}

Objetivo: Describir la experiencia de los profesionales de salud en la implementación de la Metodología de Cuidado Humanitude $(\mathrm{MCH})$ con personas mayores. Método: Se trata de un relato de experiencia sobre la aplicación de la $\mathrm{MCH}$ en un servicio de salud en Portugal, con capacidad para 30 personas ancianas, la mayoría con alteraciones cognitivas. Resultados: La implementación de la MCH demostró resultados positivos en la humanización de la asistencia a los ancianos, en particular en la reducción de los comportamientos de agitación y mejor aceptación del cuidado. Se verificó un cambio en la cultura organizacional, más enfocada en la persona y en la humanización de la asistencia. Conclusión: Los resultados apuntan la necesidad de introducir metodologías de cuidado innovadoras en la formación de los profesionales de salud, con enfoque en la interacción, para un cuidado relacional profesionalizado que dignifique a la persona cuidada y a los cuidadores.

Descriptores: Humanización de la Atención; Servicio de Salud; Enfermería Basada en la Evidencia; Atención Dirigida al Paciente; Asistencia a los Ancianos. 


\section{INTRODUCTION}

Population ageing had been contributing to the increase in the prevalence of major neurocognitive disorders (NCD) ${ }^{(1,2)}$, usually referred to as dementia in literature. Currently, it is estimated that there are about 46 million people with major NCD, with the prediction that this number will be duplicated at every 20 years, with around 131.5 million diagnosed individuals until $2050^{(3)}$. The economic global impact of major NCD is significant, having an estimated cost of 818 million American dollars ${ }^{(3)}$. It is calculated that, in 2018, this value will reach a trillion American dollars, causing implications to government authorities and to global society ${ }^{(3)}$.

Major NCDs are caused by progressive neurodegeneration, characterized by changes in specific cognitive domains, such as attention, executive function, learning abilities, memory, language, motor perception, and social cognition, affecting the autonomy ${ }^{(2)}$. These people frequently present Behavioral and Psychological Symptoms of Dementia (BPSD), such as agitation, and refusal of care, making it harder to perform care ${ }^{(4)}$.

However, one must consider that, in most cases, even with the progression of the pathology, there are no alterations in emotional perception. Thus, an individual with NCD may be deeply affected by the condition imposed by the environment and by care givers, as they may not be sufficiently prepared to care for these individuals ${ }^{(4)}$. Since the care given is not adequate, it creates a harmful environment, both for the people being cared for, since they are not understood, with the increase in anxiety and disorganization levels, and for the care givers, since they do not know how to handle the situation, potentializing emotional distress and professional dissatisfaction ${ }^{(5-7)}$.

The implementation of the Humanitude Care Methodology (MCH) has demonstrated efficacy in preventing and reducing agitation behaviors in dementia patients; acceptance of care; gains in regaining autonomy and independence of people with $\mathrm{NCD}{ }^{(5,7-9)}$. These gains in well-being and serenity provide a harmonious environment for the performance of care, positively affecting the health of care givers, and in the satisfaction and feeling of accomplishment of the professionals involved in it $\mathrm{it}^{(8,9)}$.

Researches on the implementation of $\mathrm{MCH}$ will provide further subsidy to demonstrate scientifically the positive results experienced by many health institutions in countries as France and Japan, which have gained the governments' attention. In Portugal, the process of implementing $\mathrm{MCH}$ is being performed in 43 institutions with various types of care, mostly on units of the Rede Nacional de Cuidados Continuados Integrados (RNCCI National Network of Integrated Continued Care).

\section{OBJECTIVE}

To report the experiences during the implementation of $\mathrm{MCH}$ in a Long-Term and Maintenance Unit (ULDM) and its benefits for elderly people, their families, professionals, and institution.

\section{METHODOLOGY}

\section{Type of study}

This is a experience report on the implementation of $\mathrm{MCH}$, experienced by the health professionals working at the ULDM in Portugal, according to the phases of the model for the Implementation of Practice Based on Evidence ${ }^{(10)}$.

\section{Study scenario}

In 2006, the RNCCI was created in Portugal to adapt care to the demands of people and their care givers. The main objective is to perform integrated care for the ones in dependence situation, who need continuous health care and social support, of preventive, rehabilitation, or palliative nature. Individuals with NCD are inserted in this context, as well as their family member, who frequently take on the role of informal care givers.

The RNCCl guarantees many care regimes, such as: hospitalization, ambulatorial units, hospital and homecare teams. Hospitalization units may have four types: Convalescence Units (UC), Rehabilitation and Medium-Term Units (UMDR), Long-Term and Maintenance Units (ULDM), and Palliative Care Units (UCP). The aim of the ULDMs is to provide care in order to prevent or delay the escalation of the dependence condition, optimizing as much as possible the health state, in a hospitalization period usually longer than 90 days.

The reference Unit is the ULDM, with a maximum capacity of 30 patients. The care is given by 34 professionals of different knowledge and action areas, having taken part in the experience: 11 nurses, a doctor, a physical therapist, a phonoaudiologist, a social assistant, an occupational therapist, a psychologist, 11 direct action assistant, and six service assistants. The patients were, in average, 78 years old, most of them having as the main reason for hospitalization the dependence in Daily Life Activities, due to cognitive alterations.

\section{Theoretical references}

$\mathrm{MCH}$ is an innovative care methodology, designed by Yves Gineste and Rosette Marescotti, since $1979^{(7)}$. It was implemented in many countries, such as: Canada, France, Switzerland, BelgiumLuxemburg, Germany, Portugal, Japan, and United States. With these accessions, the Institute Gineste-Marescotti (IGM) was created to organize the implementation and to structure professional formation. It has become a transversal methodology for any care, replicable in many contexts, allowing for the operationalization of the relation through five consecutive and dynamic phases: pre-preliminary, preliminary, sensorial rebouclage, emotional consolidation, and reencounter making up about 150 relational technique ${ }^{(7)}$.

Pre-preliminary techniques aim to announce the presence of care givers, open relational channels up, avoid surprise approaches, and respect privacy and autonomy. Preliminary ones anticipate the performance of care by stablishing a trust relationship by the use of relational Humanitude pillars (gaze, word, touch), and by obtaining a relational consent by the person being cared for. Sensorial rebouclage includes the performance of care, presupposing a coherent maintenance of a positive emotional ambivalence between the care giver and the person being cared for through the pillars of Humanitude (gaze, word, touch, and verticality). The emotional consolidation is a phase of cognitive and mnesic stimulus, and it allows for the emotional memory 
of the person being cared for to retain a positive impression of the relationship stablished and of the care, easing the relational consent and the acceptance of further care $^{(7)}$. The reencounter is the final moment of the relationship, when a compromise is taken for further care, thus adjusting the care to the person's will. In this phase, goodbyes are said, and a new encounter is booked, orally or written, with time references, preserving the relationship and avoiding the feeling of abandonment ${ }^{(7)}$.

For the organization and implementation of $\mathrm{MCH}$, the phases of the model for Implementation of Practice Based on Evidence ${ }^{(10)}$ were followed to better analyze the changing process $\mathrm{n}$ this institution during the four proposed phases: Raising awareness and interest creation; Knowledge and commitment construction; Promotion of action and adoption; and Accompanying the application of integration and sustainability.

\section{Experience period}

The reported experience period, since its preparation, occurred from September 2014 to December 2016. During the process of implementing the MCH in the ULDM, monthly structured interviews were carried out along with the professionals in order to identify their main difficulties in performing the care and the strategies used to overcome them.

\section{Experience evaluation}

To assess the professionals' appropriation of the $\mathrm{MCH}$, it was performed, monthly: systematic observation of care for hygiene, comfort, mobilization, and feeding, registered in a spreadsheet named Structured Sequence of Humanitude Care Procedures (SEPCH) (7), which allows for the evaluation of practical implementation of the Humanitude principles and of the operationalization of $\mathrm{MCH}$, which is composed by five consecutive and dynamic phases: prepreliminary, preliminary, sensorial rebouclage, emotional consolidation, and reencounter.

To assess the gains obtained along with patients, the following scales were applied: Braden, Morse, Barthel Index, and Mini Mental State Examination; for family and professionals, observations and structured interviews were performed.

\section{RESULTS}

The phase of "raising awareness and interest creation" was begun before inauguration of the ULDM, in September 2014, when a restricted group of health professional took part in a meeting for $\mathrm{MCH}$ sensitization, which has a positive impact on the professionals, who were interested in implementing $\mathrm{MCH}$, due to the efficacy in care practice.

With the inauguration of the ULDM, in November 2014, the professionals started to use some techniques and principles learned in the formation and sensitized their peers for the adoption of preconized MCH practices, as well as its principles. However, formal leaders identified difficulties in the implementation of $\mathrm{MCH}$, due to the lack of formation and training of techniques to professionalize the relation, and due to the difficulty in communicating to patients, specially to the ones presenting agitation and refusal of care. As the results were being unsatisfactory, leaders decided to provide a formation and capacitation of 12 health professionals for Humanitude care procedures, starting the phase of "knowledge and commitment construction".

Thus, in February 2016, the formation in Humanitude was performed, delivered and supervised by instructors certified by the Institute Gineste-Marescotti ${ }^{\circledast}$ (IGM) Portugal. This formation lasted 51 hours, including theoretical, theoretical-practical, and practical components performed directly with patients. The formation was developed in two phases: Sensitization (16 hours), involving formal and informal leaders, and Dissemination ( 35 hours), from February to April 2016, with the expectation that, in 3 months, all team professionals, due to positive contamination, would have incorporated $\mathrm{MCH}$ principles in their practice. However, it was verified that the initial formation, was not enough for an efficient capacitation and for the construction of commitment for5 all team members.

One of the difficulties faced was the nurse turnover, which caused the need for capacitating recently admitted nurses with relational techniques, so they could perform changes, caring, prescribing, and supervising care practices. Another difficulty presented was the fact that family members and informal care givers were focused on the paternalist care model, of substituting the person cared for, and, thus, they did not understand the practice of the professionals trained in $\mathrm{MCH}$, which encourages verticalization, self-care, and the promotion of autonomy.

After identifying the problems, new strategies were defined for the phase of "Promotion of action and adoption of good practices", with the creation of a support group constituted by 12 professionals that had performed both initial formation phases (sensitization and dissemination), involving formal and informal leaders. The creation of this group was a determining factor, since it allowed for the formation of a professional team with tools for strategical, operational, and leadership management, which worked as the leverage for an efficient implementation of $\mathrm{MCH}$. The support group had the function of performing monitoring and accompaniment of the implementation process, systematically collecting data on the practical application of $\mathrm{MCH}$ learned skills; identifying issues to be improved and planning more adequate strategies to implement correction measures; as well as activities that guarantee the team's adoption of Humanitude principles and care procedures.

In the sense of "Accompanying the application of integration and sustainability", the support group started to sue strategies for monitoring the implementation of $\mathrm{MCH}$ monthly, between September and December 2016, through the application of the SEPCH ${ }^{(7)}$. This systematized observation spreadsheet for the procedures performed during the care for hygiene, comfort, mobilization, feeding, among others, allowed for the evaluation of the practical implementation of Humanitude principles. Data were analyzed and presented to the team to verify the evolution and critical points needing improvements. Thus, goals were defined, as well as the development of other strategies, such as: writing slogans and banners to recall some relational procedures, such as knocking on the door, presenting oneself, thanking, booking a new encounter and saying goodbye, for the integration and sustainability of its practical application ${ }^{(10)}$. 
For the integration of new professionals, they were encouraged to take part in the formation and to receive accompaniment and supervision in care giving until the concepts, principles, and relational techniques of $\mathrm{MCH}$ were appropriated. Family members and informal care givers were more integrated in the care focused on $\mathrm{MCH}$ and they learned relational techniques to better relate to their family members, besides understanding the need for continuous stimulation of verticality, self-care, and autonomy.

The gains obtained by the professionals, elderly, family members, and the institution throughout the process of implementing this care methodology were monitored and registered on a monthly basis; For health professionals, it was verified a higher awareness of the potentialities of the person being cared for, and the understanding of their behaviors, promoting better emotion management; higher intentionality in the relationship and responsibility in the care; improvement in motivation, professional satisfaction, feeling of accomplishment; and multi-professional team work. For elderly people, it was verified a reduction in the refusal of care and of the care giver, an increase in acceptance of care, and reduction of the consumption of antipsychotic drugs. As well as the reduction in cognitive deficit, reduction of people classified as totally dependent, diminution of the risk of developing pressure injuries, and reduction of high fall risks. For family members, it was observed a bigger involvement in care, more easily understanding the behaviors of the elderly family member, and the adaptation to relational practices promoting higher approximation and interaction. For the performance of care, there was more ease in caring for elderly with dementia, reducing their agitation and increasing the acceptance of care. At an institutional level, it was verified a shift in care culture, now more focused on the humanization of assistance and on the relationships stablished to the people being cared for and to the whole multi-professional health team.

The gains obtained by the implementation of this care methodology were presented to the multi-professional team, in the sense of increasing their motivation and professional satisfaction. The results were also disseminated orally and by banners in scientific events and in publications in scientific journals.

\section{DISCUSSION}

In the process of implementing $\mathrm{MCH}$, the main difficulty was related to the lack of nurse formation on relational techniques, making it harder to appropriate and apply this care methodology in practice, which was also confirmed by another study ${ }^{(9)}$. The strategies used were related to the need to accompaniment and sensitization on the techniques that professionalize care, in agreement to other studies on this theme ${ }^{(5,9)}$. $\mathrm{MCH}$ breaks with paradigms on the possibility of being completely based on techniques for care in humanitude, and any care giver can be trained in it, regardless of having or not a empathic profile, for example. Based on the techniques, care givers develop a more conscious attention of their own and the other's perception.

The gains obtained by the implementation of this methodology are centered on professionals, elderly people, on care giving, and on the institution ${ }^{(8,9)}$. For professionals, it was clear that there was a better understanding of the behaviors of the person being cared for, better emotion management, and professional satisfaction due to the positive results obtained ${ }^{(8,9)}$. For the ones being cared for, it was highlighted the reduction of refusal of care $^{(5,8,9)}$ and the increase in the participation in self-care ${ }^{(8)}$. For care giving, it was verified more ease in the care for elderly with dementia due to the harmonious environment provided during the care. This environment is related to professional capacitation in relational techniques and to the appropriation of $\mathrm{MCH}$, which, through the structured sequence of relational procedures, eases the operationalization and systematization of the relationship in practice ${ }^{(7,9)}$, avoiding the performance of forced and unexpected care, creating, for the ones being cared for, a feeling of having their freedom respected, as well as their dignity and autonomy, contributing for the reduction of agitation and increasement of acceptance of care ${ }^{(5)}$. At an institutional level, it was observed a shift in care culture, creating an environment and organizational atmosphere that can promote assistance humanization ${ }^{(8,9}$.

\section{Study limitations}

The limitations are related to the fact that the implementation of training, capacitation, accompaniment, and evaluation of managers and professionals to act on $\mathrm{MCH}$ was tested, as a whole, in a determined ULDM. It is necessary to test the implementation process, as reported, in other ULDMs.

\section{Contributions for the nursing, health or public policies areas}

The report of this $\mathrm{MCH}$ implementation experience, as an innovative care technology, and of the efficacy of the gains will allow for new perspectives in the nursing care, uniting technicity, technology, and clinical scientific evidence criteria, having the essence of humanitude as the basis for the formation and action of nurses, contributing to a shift in care culture and in public health policies, specially in the context of elderly population and their family members. This methodology allows for the increase in care effectiveness and in the satisfaction of care givers.

\section{CONCLUDING REMARKS}

The implementation of $\mathrm{MCH}$ is a process that requires accompaniment and monitoring for the sustainability and consolidation of good practices by all professionals, as well as the effective participation of managers in order to obtain better results. The shift in care culture is a challenge, since professionals are sometimes used/formatted to certain care practices and need, in a first phase, to be sensitized on the evidences of innovative care methodologies to accept and recognize practices in need for improvements and, thus, to perform the process of capacitation and adoption of new care practices.

The evidence of the positive results of this care methodology leads to reflections on the need for changes in the formation of health professionals, in the paradigm of care focused on tasks, towards a relational professionalized care, which promotes a more democratic society, respecting the dignity, autonomy, and liberty of the person being cared for and the care giver. 


\section{REFERENCES}

1. Prince M, Bryce R, Albanese E, Wimo A, Ribeiro W, Ferri CP. The global prevalence of dementia: a systematic review and metaanalysis. Alzheimers Dement [Internet]. 2013 [cited 2017 Mar 27];9(1):63-75. Available from: https://doi.org/10.1016/j.jalz.2012.11.007

2. American Psychiatric Association (APA). Diagnostic and statistical manual of mental disorders. 5th ed. Arlington: American Psychiatric Association Publishing; 2013 [cited 2019 Feb 9]. Available from: https://doi.org/10.1176/appi.books.9780890425596

3. Prince M, Wimo A, Guerchet M, Ali MGC, Wu YT, Prina M. World Alzheimer Report 2015: the global impact of dementia: an analysis of prevalence, incidence, cost and trends. [Internet]. London: Alzheimer's Disease International; 2015 [cited 2017 Mar 27 ]. Available from: https://www.alz.co.uk/research/WorldAlzheimerReport2015.pdf

4. Hughes JC, Beatty A. Understanding the person with dementia: a clinic philosophical case discussion. Adv Psychiatr Treat [Internet]. 2013 [cited 2017 Mar 27];19(5):337-43. Available from: https://doi.org/10.1192/apt.bp.112.011098

5. Honda M, Ito M, Ishikawa S, Takebayashi Y, Tierney Jr L. Reduction of behavioral psychological symptoms of dementia by multimodal comprehensive care for vulnerable geriatric patients in an acute care hospital: a case series. Case Rep Med [Internet]. 2016 [cited 2017 Mar 27] Article ID 4813196:1-4. Available from: https://doi.org/10.1155/2016/4813196

6. Kable A, Guest M, McLeod M. They dare to resist care: nurses report experiences with patient resistance to care. J Adv Nurs [Internet]. 2013 [cited 2017 Mar 27];69:1747-60. Available from: http://www.medscape.com/viewarticle/810264

7. Melo RCCP, Queirós PJP, Tanaka LH, Salgueiro NRM, Alves RE, Araújo JP, et al. State-of-the-art in the implementation of the humanitude care methodology in Portugal. Rev Enf Ref [Internet]. 2017 [cited 2019 Feb 9];4(13):53-62. Available from: https://doi.org/10.12707/RIV17019

8. Henriques LVL, Dourado MARF, Melo RCCP, Tanaka LH. Implementation of the humanitude care methodology: contribution to the quality of health care. Rev Lat Am Enfermagem [Internet]. 2019 [cited 2019 Feb 9];27:e3123. Available from: https://doi. org/10.1590/1518-8345.2430-3123

9. Figueiredo AMG, Melo RCCP, Ribeiro OP. Humanitude care methodology: difficulties and benefits from its implementation in clinical practice. Rev Enferm Ref [Internet]. 2018 [cited 2019 Feb 9];4(17):53-62. Available from: https://doi.org/10.12707/RIV17063

10. Cullen L, Adams SL. Planning for implementation of evidence-based practice. J Nurs Adm [Internet]. 2012 [cited 2017 Mar 27];42(4):222-30. Available from: https://doi.org/10.1097/NNA.0b013e31824ccd0a 